\title{
Effects of COVID-19 on Sudanese Enterprises
}

December 2020 


\section{FOREWORD}

Many studies and surveys were conducted to assess the effects of the COVID-19 pandemic, and many have shown negative effects, not only on health, but also on the economic, social, legal, environmental, and cultural aspects. In addition to causing a large number of injuries and deaths, the pandemic has also affected access to necessary services and goods, social relations, cultural aspects, revenues, income levels, commercial relations nationally, regionally and internationally, the labor market and employment, ongoing work contracts, psychological; stress and depression and environmental.

The Central Bureau of Statistics (CBS) as the main producer of official and reliable statistics in Sudan and the coordinator of the National Statistics System (NSS), responsible for organizing the statistical framework for the NSS to guide and inform policy formulation, planning and decisionmaking processes, conducted a High Frequency Survey in partnership with the World Bank to assess the impact of COVID-19 on Sudanese households and enterprises. The survey which is the sole exercise taking place in Sudan aims to inform policymaking, strategic planning, and government responses to contain the impact of the pandemic to its lower possible level.

This is the time to help monitor and mitigate the effects of the crisis by taking some measures and actions by the different sectors that support evidence-based response to the current crisis. The survey covered households in all states of Sudan in urban and rural areas, as well as small and medium enterprises in Khartoum state.

In conclusion, I hope that communication will continue with all sectors to provide all available data and statistics in support of their effort and work in full partnership to implement the planned statistical operations in Sudan.

Finally, I would like to thank the World Bank for working in fully partnership with CBS all through the survey process and also thanks to CBS technical staff and Stat Solution for carrying out this survey with professional and skills.

\section{Ali Mohamed Abbas Ahmed, Director General, Central Bureau of Statistics, SUDAN.}




\section{ACKNOWLEDGMENTS}

This report is based on data from the first round of the Sudan High Frequency Survey on COVID-19, collected during August 2020. The panel survey is implemented jointly by the Central Bureau of Statistics (CBS) and the World Bank.

The report was prepared by a core team consisting of Fareed M. A. Hassan (Consultant, World Bank); Alvin Etang Ndip (Senior Economist, World Bank); Eiman Osman (Consultant, World Bank); Amin Daoud, Huda Osman, Hanan Siddik, and Adil Sied Ahmed (CBS); and Siddik Shaheen (Professor, University of Khartoum), with overall guidance provided by Ali Abbas (Director General, CBS).

Asta Bareisaite and Arti Grover (World Bank's Finance and Competitiveness team) contributed substantially to the survey design. The survey also benefited from contributions from other CBS staff including Randa Ibnoof, Noor Mohamed, Taqwa Mohieldin, Athar Osman, Sara Hamad, and Abeer Mohd. Abdelmagid.

The report would not have been possible without the relentless efforts of Stat Solutions, a local consulting firm assisting with the data collection. Many thanks to Hussam Atta Elmanan, Walaa Ibrahim, Fathi Osama, and Ayat Abass and to the interviewers and supervisors. The survey also benefited from the contribution of Mohamed Nimir (Consultant, Sudanese Businessmen and Employers Federation) and Elfatih Ali Siddig (Freelance Consultant).

The team benefited from the valuable advice and feedback of Pierella Paci (Practice Manager, World Bank) and Milena Stefanova (Sudan Country Manager, World Bank). Christina Wieser (Senior Economist, World Bank) and Maisoun Alaaidin Badawi (Consultant, World Bank) were peer reviewers for the report. Inputs from staff at the World Bank are also gratefully acknowledged.

An early draft of the report's main findings was presented at a virtual workshop co-chaired by the Director General of the Central Bureau of Statistics and the World Bank Country Manager on Sunday December 6, 2020. The workshop convened about 60 participants including government officials, representatives from Sudanese Businessmen and Employers Federation, private sector, and civil society. The workshop discussed key challenges and opportunities for improving enterprise performance during the pandemic. Feedback from the workshop has been incorporated in this report.

The UK's (Foreign, Commonwealth and Development Office) financial contribution to the World Bank's Sudan poverty program facilitated implementation of this survey and is highly appreciated. 


$\begin{array}{ll}\text { ABBREVIATIONS AND ACRONYMS } \\ \text { AfDB } & \text { African Development Bank } \\ \text { CATI } & \text { Computer Assisted Telephone Interviews } \\ \text { CBoS } & \text { Central Bank of Sudan } \\ \text { CBS } & \text { Central Bureau of Statistics } \\ \text { GDP } & \text { Gross Domestic Product } \\ \text { GoS } & \text { Government of Sudan } \\ \text { HEPRTF } & \text { Health Emergency Preparedness and Response Trust Fund } \\ \text { ICT } & \text { Information and Communication Technology } \\ \text { IMF } & \text { International Monetary Fund } \\ \text { ISIC } & \text { International Standard Industrial Classification } \\ \text { LPI } & \text { Logistics Performance Index } \\ \text { MSMEs } & \text { Micro, Small, and Medium Enterprises } \\ \text { SMEs } & \text { Small and Medium Enterprises } \\ \text { STARS } & \text { Sudan Transition and Recovery Support Trust Fund } \\ \text { WHO } & \text { World Health Organization } \\ \end{array}$




\section{TABLE OF CONTENTS}

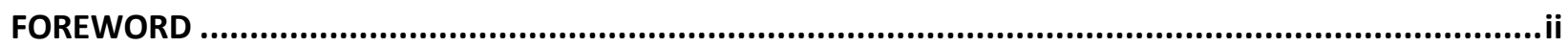

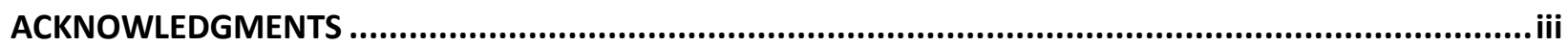

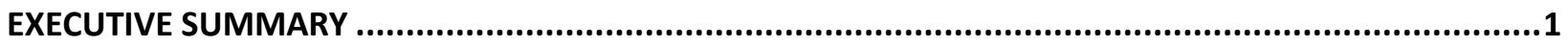

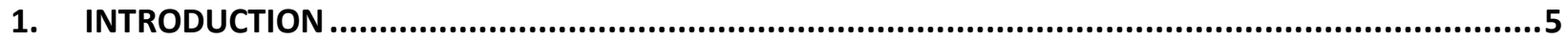

2. SURVEY METHODOLOGY AND SAMPLING FRAMEWORK ......................................................6

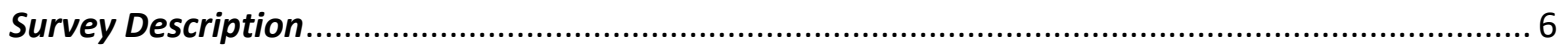

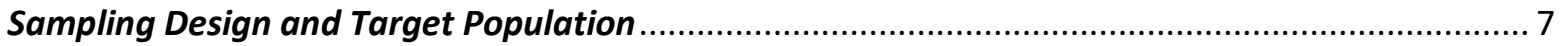

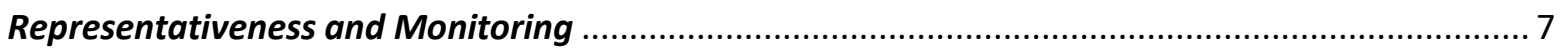

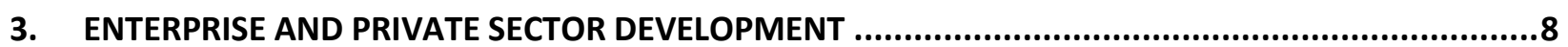

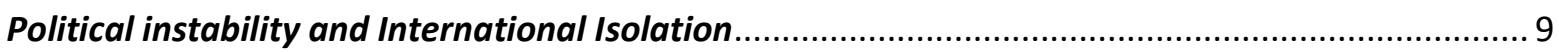

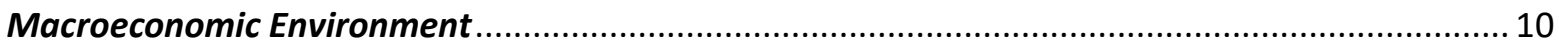

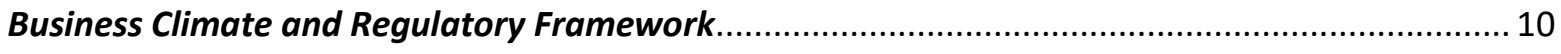

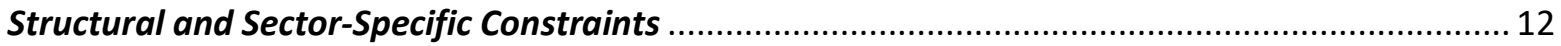

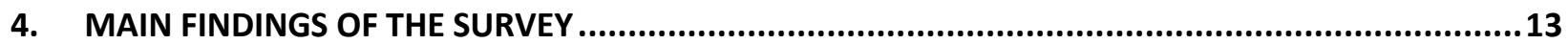

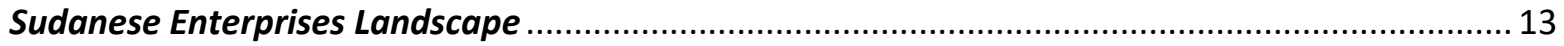

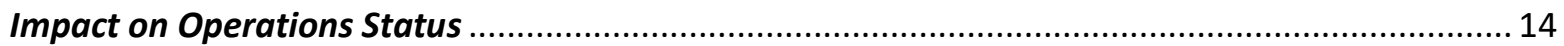

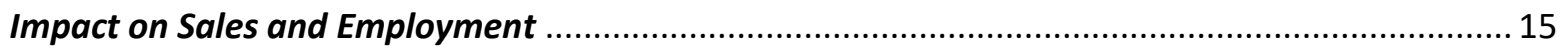

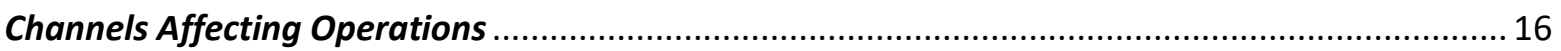

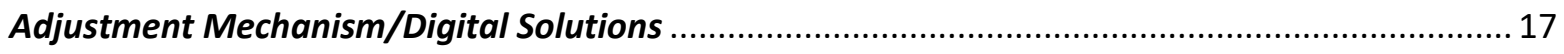

Enterprise Perceptions and Government Policies ..................................................................... 18

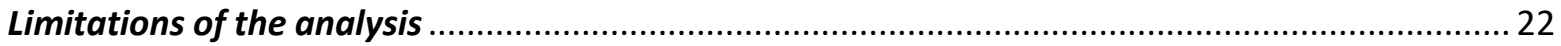

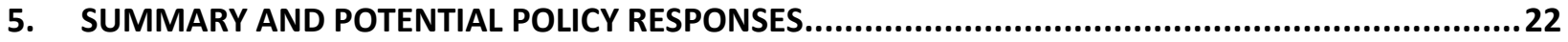

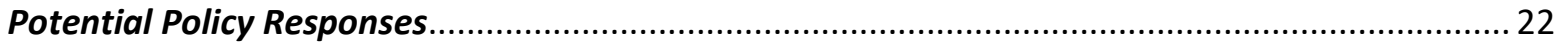

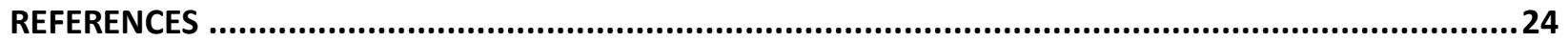


As with other countries, Sudan has been hit hard by the COVID-19 pandemic. The Sudanese authorities attempted to act quickly in the face of the spreading virus. The Government has established a high-level emergency committee to oversee the operations to deal with the COVID-19 pandemic. The Government imposed closure of schools, airports, ports, and land crossings; banned travel between states; and prohibited mass gatherings. A partial lockdown was imposed in Khartoum State. Restrictions on movement are expected to make the economic situation worse, with commodity prices soaring across the country. The rapid spread of COVID-19 in Sudan and the Government's containment measures could negatively affect business enterprises of all kinds-including enterprise closings; loss of sales and employment; and decreased access to finance, cash flow, inputs, and raw materials-particularly those with smaller operating margins, such as micro, small, and medium enterprises (MSMEs).

In addition to COVID-19 impacts, major constraints are affecting the performance and employment levels of business enterprises, particularly private MSMEs. These constraints include political and macroeconomic instability, particularly inflation and exchange rate volatility, a weak financial system, a restrictive business climate (onerous customs and taxes procedures and competition from public enterprises), poor infrastructure (electricity, internet and broadband, and transport), and low-quality education and skills training.

The objective of the Sudan High Frequency Survey on COVID-19 is to quickly collect enterprise-level information, using phones, to monitor the crisis and assess the dynamics of the impacts of COVID-19 on MSMEs in Sudan. The survey is expected to help inform dialogue and mitigation measures. The survey focuses on the impacts of COVID-19 on MSMEs' performance and provides near real-time data, supporting an evidence-based response to the crisis. It should be noted that the MSMEs' performance is not only affected by COVID-19 but also the abovementioned constraints that have adversely affected enterprises.

The survey is implemented jointly by the Central Bureau of Statistics (CBS) and the World Bank. As faceto-face surveys were not feasible, the survey was conducted using mobile phones and covers Khartoum State, where most of the Sudanese enterprises are located. The survey will monitor the impact of coronavirus on the operation of enterprises that are being interviewed, with a panel of nearly 500 formal enterprises. The survey sample frame is derived from eligible enterprises obtained from the Central Bureau of Statistics, Sudanese Businessmen and Employers Federation and marketing databases. The sampling methodology for the survey is stratified random sampling and the strata for the survey are enterprise size and business sector, consistent with the International Standard Industrial Classification (ISIC). Round 1 of data collection was conducted during August 2020. It is planned to be repeated every 2-3 months.

The key findings of the survey are summarized in terms of enterprise closings, impact on sales and employment, channels affecting operations, adjustment mechanisms, enterprise perceptions, and government policies. 


\section{Enterprise Closings}

- Over 70 percent of the surveyed enterprises are micro, employing less than five workers, and the sector breakdown shows the dominance of retail and other sector (transport, storage, utilities) enterprises.

- $\quad$ Of the surveyed enterprises, 29 percent had to close during the partial lockdown, with 8 percent permanently closed, and 21 percent temporarily closed.

- Small enterprises (5-19 employees) were the most affected by the partial lockdown where nearly half had to close. In contrast, around one-third of medium (20-99 employees) and large (100 and more employees) enterprises closed. Only one-quarter of the micro enterprises (0-4 employees) had to close.

- The sectors with the highest level of closures during the lockdown were manufacturing and other services (about 50 percent).

\section{Impact on Sales and Employment}

- Of the enterprises that are open, 81 percent reported that sales in August 2020 decreased compared to the same month in 2019. The average decrease in sales was 54 percent. Enterprises in manufacturing (83 percent) and other services (81 percent) were largely affected.

- $\quad$ About 7 percent of the enterprises report that they reduced wages for an average of 6 percent of their workforce while 8 percent of the enterprises indicate that they have laid off workers, corresponding to 5 percent of the workforce.

\section{Channels Affecting Operations}

- $\quad$ Nearly all enterprises (97 percent) indicate a decrease in hours worked, 87 percent witness a decrease in demand, 72 percent face difficulties in finding input, and nearly 50 percent report cash flow problems and decreased access to finance.

- $\quad$ Significant differences exist in the share of enterprises affected by both demand and production shocks (that is, decrease in hours worked, cash flow, and availability of finance and inputs) across enterprises. Medium enterprises (with a share of 93 percent) were the most effected, followed by the small and micro enterprises (with a share of 86 percent). Large enterprises (with a share of 70 percent) were more resilient to shocks than others. In terms of sector breakdown, the other services sector is the most affected.

\section{Adjustment Mechanisms}

- To cope with COVID-19 restrictions, about 11 percent of the enterprises started or increased their use of internet, online social media, specialized apps, or digital platforms to do business.

- $\quad$ Enterprise use of internet to do business is not only small (11 percent) but also varies significantly across enterprises. While 25 percent of large enterprises either adopted or 
increased the use of internet for their operations, small and medium enterprises were the ones that adopted or increased the use of internet the least.

\section{Enterprise Perceptions and Government Policies}

- Financial problems perceived by enterprises as top obstacles to their operation include meeting staff wages and social security charges, paying rent, repaying loans, paying invoices, and accessing banking services.

- $\quad$ Enterprises report that measures improving liquidity (cash transfers, fiscal exemptions or reductions, tax deferral, access to new credit, and deferral of rent payment) are the most desired policies to support enterprises during the pandemic.

- The Government has implemented limited measures to mitigate the effects of the pandemic. The Government has directed commercial banks to provide some concessions to enterprises in terms of loan payment deferral following the pandemic and to allocate 15 percent of their portfolio to microfinance. However, microfinance has not exceeded 6 percent of the banks' portfolio. An Investment and Private Sector Development Authority (IPSDA) was created in December 2019 as a one-stop-government institution to cater for the private sector, its needs and challenges. IPSDA has already embarked on its reform agenda, including drafting of a new Investment Law and Public-Private Partnership Law. However, these measures have not been effectively communicated to the enterprise sector.

- None of the enterprises received public support in July 2020, and 62 percent of them indicated that they were not aware of support programs. This suggests the need for increased awareness and clarity on the guidelines and requirements of current support polices.

Potential policy responses emerge from the key findings. COVID-19 and the constraints facing the realization of economic growth and job creation through developing the enterprise sector are to be addressed in an integrated multi-sector approach as many factors are affecting enterprise performance at the same time of the COVID-19 pandemic. The approach encompasses short, medium, and long-term policy response. Immediate COVID-19 response interventions include designing enterprise support schemes and facilitating access to finance, while medium to longer-term interventions focus on strengthening the business climate (that is, reforming the governance system of enterprises, building reliable data sources of enterprises, and upgrading infrastructure).

- $\quad$ Design enterprise support schemes that improve liquidity (cash transfers and deferral of payments) to ensure that businesses are returned to their state before the pandemic. Enterprises report that measures improving liquidity are the most desired policies, and these short-term policy responses are expected to help enterprises sustain their activities and minimize layoffs.

- Facilitate access to finance adapted to enterprise needs. Policy measures that ensure availability of adequate finance adapted to MSME needs include providing a supporting framework for enhanced credit information and bank competition and developing a modern credit reporting system and electronic collateral registry for movable assets. 
- $\quad$ Reform the governance system of enterprises. Develop a law to support small and micro enterprises and formulate a specialized national entity dealing with their specific needs and challenges. The overlap of the roles and responsibilities of the institutions responsible for MSMEs and weak coordination among them constrains their capacity to set policies, strategies, and plans for their development. Strengthening the capacity of the recently established Investment and Private Sector Development Authority will be key to streamlining and accelerating the reform process.

- $\quad$ Build reliable data sources for enterprises Collecting data on MSMEs by number of employees, turnover, and asset size would help develop a definition of MSMEs as well as identify and quantify underserved MSMEs segments. Developing computerized business registries would further facilitate the data gathering process. Annual business and financial reports can provide important measures over time on the size and trends of the enterprise sector.

- Upgrade key infrastructure to enhance enterprise capabilities to cope with shocks. Enterprise use of internet to do business is low. Improving access to key infrastructure (for example, reliable electricity supply and internet and higher broadband access rates) and enhancing policies that facilitate adoption of digital solutions and expanding access to markets and inputs would improve enterprise production capabilities to cope with shocks. 
Following the outbreak of COVID-19 in Sudan, the Government established a high-level emergency committee to oversee the operations to deal with the COVID-19 pandemic. Sudanese authorities attempted to act quickly in the face of the spreading virus. With the confirmation of the first COVID-19 case in Sudan on March 13, the Government of Sudan (GoS) declared a 'state of emergency'. On March 14,2020 , the Government announced closure of schools and prohibition of mass gatherings. Two days later, it closed airports, ports, and land crossings; banned travel between states; and required a onemonth quarantine for incoming travelers. On March 25, 2020, authorities released 4,217 prisoners as a precautionary measure to reduce the risk of transmission in detention. A night curfew was imposed from 6:00 p.m. to 6:00 a.m., while the State of Khartoum announced a partial lockdown for three weeks, starting April 18. People could move within their districts between 8:00 a.m. and 1:00 p.m. (which was later further extended to 3:00 p.m.), with restrictions on crossing bridges into the three districts of the state, Khartoum, Bahri, and Omdurman.

The lockdown was further extended until July 7. Starting July 8, 2020, Sudan began loosening the lockdown measures in and around the capital Khartoum after three months of tight restrictions. The airport began opening on July 12. According to the Multi-hazard Emergency Health Preparedness Plan prepared by the Government and guided by the World Health Organization (WHO), the financing needs to cope with COVID-19-related health care are about US\$230 million. The plan is currently underfunded, and the needs are imminent especially with the expected second wave and the recent deadly flooding in the country. Despite the significant efforts made by the Government and other key partners, the progress under the plan has been relatively slow under most of the pillars due to the lack of funding and the delayed procurement of required supplies. A revised draft federal budget for 2020 includes a major emergency allocation of resources for COVID-19-related expenditures.

Despite the containment measures, the COVID-19 transmission in Sudan evolved quickly. As of October 14, 2020, the GoS reported 13,691 confirmed cases and 836 fatalities. Sudan has limited capacity at present to control the transmission and contain the COVID-19 pandemic and is among the most affected African countries in terms of numbers of confirmed cases and deaths. The crisis has brought to the fore systemic weaknesses in Sudan's health system. The COVID-19 pandemic threatens to disrupt the provision of essential health care services due to barriers to the supply and demand for services. COVID-19 will lead to increased prices of basic foods, rising unemployment, slower growth, higher deficits, and falling exports. Restrictions on movement are making the economic situation worse, with commodity prices soaring across the country. According to the Central Bureau of Statistics (CBS), inflation rose from 82 percent in March 2020 to 212 percent in September. The World Bank projects gross domestic product (GDP) to decrease 4-10 percent in 2020 due to the combined impact of the economic crisis exacerbated by the social distancing measures to curb the spread of COVID-19. Slowing economic growth, including curtailed enterprise activities, and COVID-19 policy responses will have a significant negative impact on government revenue. Slowing economic activities translate into lower levels of tax and other government revenue collection.

The pandemic is expected to affect the micro, small, and medium enterprises (MSMEs) sector through a multiplicity of channels, including demand shocks, supply shocks, and financial shocks. The rapid spread 
of COVID-19 in Sudan and the Government's containment measures could negatively affect entrepreneurs that have been curtailed, if not closed their businesses, at least temporarily.

There is an urgent need for timely data and evidence to help monitor and mitigate the impacts of the crisis. However, face-to-face surveys are not currently feasible in Sudan, as in many other countries directly affected by COVID-19 due to the risk of infection as well as mobility restrictions. The use of phone surveys is an alternative. Phone surveys can collect data without visiting enterprises. They can be implemented rapidly and at low cost, form a baseline for follow-up surveys, and adapted swiftly to changing circumstances. Thus, phone surveys are highly suited for rapid data collection especially in emergencies and under very rapidly changing conditions. While the literature is limited for developing countries, there is evidence that mobile phone surveys can be effective (for example, see the World Bank Listening to Africa project; Dabalen et al. 2016; Leo et al. 2015) and telephone surveys were successfully used in Ghana to study How COVID-19 Is Affecting Firms in Ghana (World Bank 2020a).

The objective of the Sudan High Frequency Survey on COVID-19 is to provide critical information to monitor the effects of the pandemic on businesses in Khartoum State. The survey provides timely data that help inform dialogue and mitigation measures.

The report proceeds as follows. Following this introductory section, Section 2 describes the methodology and sampling design used for the Sudan High Frequency Survey. Section 3 sets the stage, analyzing several structural and sector-specific constraints affecting the enterprise and private sector development in addition to the COVID-19 pandemic. Section 4 presents the main findings of the survey, examining the impact of the pandemic on enterprises including disruptions to operations, impacts on sales and employment, and channels affecting operations, as well as needed government policies to support enterprises during the pandemic. Section 5 provides a summary of potential policy responses.

\section{SURVEY METHODOLOGY AND SAMPLING FRAMEWORK}

\section{Survey Description}

The Sudan High Frequency Survey on COVID-19 is implemented using mobile phones (that is, live interviews from a call center) on a semi quarterly basis, making use of the existing lists of phone numbers across Khartoum State. The survey sample frame is derived from eligible/formal enterprises obtained from the Central Bureau of Statistics, Sudanese Businessmen and Employers Federation and marketing databases. The strata for the survey are enterprise size and business sector. According to the World Bank enterprise survey methodology, enterprise levels are less than 19 employees (small), 20-99 employees (medium), and 100+ employees (large enterprises) (World Bank 2014). Since most of the Sudanese enterprises are very small, the category of micro enterprises employing less than 5 employees is added. For the business sector, the International Standard Industrial Classification (ISIC) Version 3.1 is used as a reference for business sector classification (for example, agriculture, fishing, mining, manufacturing, construction, retail, transportation and storage, accommodation, food service, and so on). The existing lists of enterprise mobile phone numbers across the three districts of Khartoum State (that is, Khartoum, Bahri, and Omdurman) make sampling from the lists feasible. Enterprises without telephones have no chance of selection, obviously, as do those that are not included on the lists. Round 1 of data collection 
was conducted during August 2020. It is planned to be repeated every 2-3 months over a period of 6-12 months.

Given the rapidly evolving situation around COVID-19, the Round 1 survey operation had the following specific components, not common in a 'typical' phone survey operation with the need for the survey firm to pay attention to the following (especially at the beginning of the survey). First, interviewers had to work from their own home when the call centers could not be operated because of the restrictions of movement and assembly of people. Second, training of interviewers had to be carried out remotely (because of home-based work), and a sound training plan was provided as part of this project. Third, supervision and interviewer follow-up also had to be undertaken remotely.

The interviews for the selected enterprises were done through telephone, and data collection for the survey was done using tablets and the Kobo application (Computer Assisted Telephone Interviews, CATI). The questions revolve around the impacts on enterprises, including channels affecting operations such as hours worked, demand, cash flow, supply of inputs and raw materials, and enterprise perceptions on needed public policies.

\section{Sampling Design and Target Population}

The sampling methodology adopted for the implementation of this survey is probabilistic. Each of the units in the targeted population of the study must have a nonzero probability and know in advance that they are part of the selected sample. This approach has the advantage of allowing, on the one hand, extrapolating the results of the sample and, on the other hand, estimating the precision of the results obtained. However, the implementation of this approach requires the availability of an adequate sampling frame containing all the units of the population and without omissions or duplications. ${ }^{1}$

The evaluation of data quality of this survey must be based not only on the reduction of sampling errors but also on reduction of non-sampling errors. In this sense, effort must be made at each of the multiple steps of conducting the survey, starting with the conception of the survey documents and methodological approaches and ending with data analyses and dissemination.

In Sudan, under the present federal system, the state is considered as a semiautonomous entity mandated to take care of the affairs of the citizen and provide governance and be responsible for planning, policy formulation, and implementation of the annual program. This sample survey covers Khartoum State, where most of the country's enterprises are located. A total of 489 enterprises were interviewed during the first round of data collection (conducted during August 2020).

\section{Representativeness and Monitoring}

As noted earlier, due to the coronavirus outbreak, it is difficult to collect enterprise survey data by faceto-face interviews in Sudan, as with many countries in Africa. However, there is demand for collecting data on disruptions to the operations of enterprises, employment and sales, shocks, and policies. Given

\footnotetext{
${ }^{1}$ Ideally the survey sample frame is derived from the universe of eligible enterprises obtained from the country's statistical office. However, there are major data limitations as industrial and labor force surveys have not been conducted for years. The latest enterprise survey was conducted by the World Bank in 2014 (World Bank 2014).
} 
the difficulties of collecting data in person, the use of phones is an attractive option, but it has its own limitations. For example, phone surveys run the risk of error in resulting estimates because of either under-coverage or nonresponse.

Under coverage is a major concern for phone surveys implemented in developing countries. Enterprises without phones and those with mobile phones but outside of areas with network coverage would be under covered by a phone survey. The risk of nonresponse is a concern for all panel surveys, particularly phone surveys. Efforts will be made to minimize this risk, including follow-up with respondents who fail to respond and keeping the interviews short (15-20 minutes) to reduce respondent fatigue. Reweighting techniques can be used to correct for this but will depend on observable characteristics.

The phone survey may not be representative of all enterprises in Khartoum State. However, by collecting data from the same enterprises frequently, changes in operations status, sales, employment, and policy interventions over time can be monitored. This information will be highly valuable for policy makers.

\section{ENTERPRISE AND PRIVATE SECTOR DEVELOPMENT}

Small and medium enterprises (SMEs) play a major role in economic development. A recent study by the International Monetary Fund (IMF) suggests that SMEs account for over 90 percent of all business and provide a major source of new job creation in the Arab economies (IMF 2019). ${ }^{2}$ SMEs' contribution to GDP in Arab economies ranges between 4 percent and 40 percent, while their contribution to employment accounts for 10 percent to 40 percent of all employment. These estimates reflect the potential for a larger role for SMEs in some economies as well as their already significant role in others. In developing economies, formal SMEs contribute up to 45 percent of employment and up to 33 percent of GDP (IFC 2010). These numbers are significantly higher when considering the estimated contributions of SMEs operating in the informal sector. In developed countries, SMEs contribute nearly 64 percent to the GDP and 62 percent to employment (IFC 2017).

The formal private sector in Sudan is characterized by MSMEs and a few large companies, many of which are state-owned. MSMEs account for most private business activity in Sudan, and the few large companies that exist are clustered in trade and industrial processing areas and mostly located in Khartoum state, as few other places in the country offer the necessary infrastructure for large-scale commercial activities. The resource sectors (oil and gold) have been the primary source of economic growth in recent years; however, by nature, these are enclave industries. A large proportion of the private sector in Sudan is informal due to the breakdown of trust in market institutions and social networks.

A dedicated MSME sector strategy is missing in Sudan; a unified definition of MSMEs does not exist; and enterprise data is nor regularly collected. MSMEs are incorporated into broader strategies and plans, objectives, and pillars. For example, Sudan's Five-year (2015-2019) Economic Reform Program highlighted economic diversification as a key pillar. Sudan still does not have a law to support MSMEs nor a specialized national entity dealing with their specific needs and challenges. The overlap of the roles and responsibilities of the institutions responsible for SMEs and weak coordination among them limits their

\footnotetext{
2 The Arab World: Algeria, Bahrain, Djibouti, the Arab Republic of Egypt, Iraq, Jordan, Kuwait, Lebanon, Libya, Mauritania, Morocco, Oman, Qatar, Saudi Arabia, Somalia, Sudan, Tunisia, United Arab Emirates, West Bank and Gaza, and the Republic of Yemen.
} 
capacity to set policies, strategies, and plans for their development. In the Central Bank of Sudan (CBoS) policy of 2019, there was no specific mention of MSMEs, and the policy stated that no less than 15 percent of the lending portfolio of banks should be directed toward microfinance. However, a unified definition of MSMEs does not exist in the banking system. The financing policies of the CBoS combine craftsmen, professionals, and small producers, including the productive families, into one category and define this sub-sector by the volume of financing from commercial banks. Data on enterprises are not timely collected, and the latest enterprise survey was conducted by the World Bank in 2014 that covered 662 enterprises in Khartoum State distributed among Bahri (42 enterprises), Khartoum (489 enterprises), and Omdurman (131 enterprises).

Official data on MSMEs' contribution is lacking; however, private investment performance deteriorated since 2014. Private investments to GDP declined from 18.0 percent in 2014 to 16.7 percent in 2017. The growth rate in private investments sharply declined from 34.6 percent in 2014 to only 12.7 percent in 2017 (Figure 1). The share of private investment in total investments declined from 94 percent in 2014 to 80 percent in 2017 indicating crowding out of private investments.

Figure 1: Private Investment Performance, 2014-2017

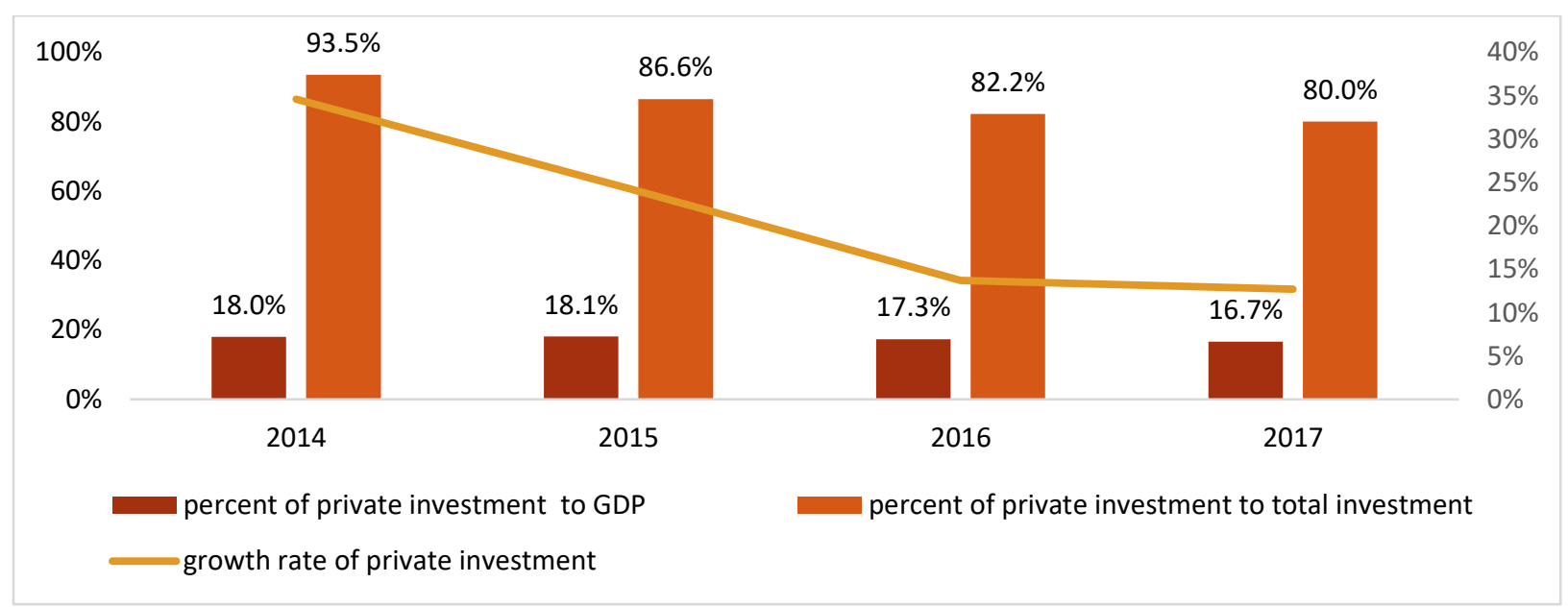

Source: CBoS Annual Reports.

Decline in private investments is due to many factors/constraints. Despite the potential of MSMEs in terms of their contribution to GDP and employment, they face several constraints. These constraints are related to political instability and international isolation, macroeconomic conditions, business climate, and regulatory framework, as well as structural and sector-specific constraints. These constraints have a more negative impact on smaller enterprises than large ones. The COVID-19 pandemic and the recent floods have compounded the constraints faced by the sector.

\section{Political instability and International Isolation}

Years of conflict and economic isolation have disrupted economic activity, market institutions and essential services, particularly for MSMEs. Due to conflict, state government structures are often weak with limited capacity and unable to deliver essential services. Weak infrastructure is common throughout the country and more particularly in conflict areas. The absence of a properly functioning and accountable 
state, and corruption have permeated transactional norms facing the domestic private sector and foreign investors.

Years of isolation and the presence of Sudan on the U. S. list of state sponsors of terrorism for nearly thirty years, have limited enterprise's global and local value chain linkages. While the United States lifted economic sanctions in October 2017, international relationships were not fully normalized, and the economy continued to face economic challenges. The 1997-2017 U.S. sanctions included a trade embargo and restrictions on financial institutions dealing with Sudan. This has narrowed market coverage and trade activities to limited market points to the Gulf countries and south east Asia, where the flow of inputs from goods to raw material were severely impacted. Access to financial markets further tightened in 2014, prompting several international banks to review and restrict transfers that may eventually end up in Sudan and resulting in overcompliance and further increases in the cost of doing business. Lifted in October 2017, the removal of the sanctions has had little impact on the economy as the country remained on the List of State Sponsors of Terrorism from 1993 to December 2010 and therefore has no access to external finance, technology, and knowhow. While the delisting of Sudan from the List of State Sponsors of Terrorism on December 14, 2020 will likely bring some new investment and may open a path to negotiations regarding debt relief, a full recovery and normalization of relations with creditors will require further reforms.

\section{Macroeconomic Environment}

The Sudanese private sector, particularly MSMEs, operates in one of the most challenging economic environments in the world. The economic instability in the form of high inflation and unstable exchange rate caused many businesses to halt their activities being unable to predict their business future. Large macroeconomic imbalances and economic contraction since 2018 are set to intensify sharply in 2020, undermining commercial activity of the private sector. The fiscal position deteriorated in 2018-2019 primarily because of rising government expenditure and declining revenue, and COVID-19 brought additional unexpected budgetary challenges in 2020. The fiscal deficit rose rapidly, from 6.50 percent of GDP in 2017 to 10.75 percent of GDP in 2019. With the low level of external financing and grants, the budget deficit has been monetized, driving inflation to 212 percent in September 2020, compared to 64 percent in January. While the monetization of large public sector deficits fueled rapid inflation, the limited supply and shortages of good and services during the pandemic exacerbated the problem. The parallel/market exchange rate has depreciated considerably (200 percent) since March 2020.

The combination of the global economic crisis and domestic limitations triggered by COVID-19 is expected to lead to a 4-10 percentage point decline in growth in 2020 (World Bank 2020b). GDP growth slowed to under 2 percent on average during 2012-2017. With the COVID-19 emergency and lockdown, the contraction of GDP in 2020 is estimated to reach 4-10 percent. In addition, the July-September floods have led to some 100 fatalities and the destruction of 100,000 homes affecting over 500,000 people, promoting the declaration of a state of emergency.

\section{Business Climate and Regulatory Framework}

Doing business reform has regressed and Sudan's Doing Business rank slipped by 9 places compared to its 2019 ranking. Sudan ranks low-171 out of 190 countries - on ease of doing business in the 2020 World 
Bank Doing Business Survey, slipping by 9 places compared to its 2019 ranking. Having access to credit, trading across borders, protecting minority investors, and paying taxes are identified as major weaknesses. According to the Enabling the Business of Agriculture report (World Bank 2019), with an aggregate score of 29.27, Sudan is far behind its neighboring countries Egypt and Ethiopia. Meanwhile, Sudan's logistics performance today is on par with developing countries across all categories of the logistics performance indexes (LPIs), except for timeliness. The noticeable change is that Sudan's LPI is worse today relative to in 2007, when it was performing better than other developing countries. Similarly, in terms of trade facilitation (for example, governance and information availability), Sudan is currently performing worse than developing countries across all categories.

Policies and incentives for the private sector have not been conducive to investment. Sudan's private sector perceives customs and trade, taxes, political instability, and corruption as the main reasons for holding back investment and business development (2014 World Bank Enterprise Survey). Other constraints include inadequate infrastructure services such as transport and access to finance (Figure 2).

Figure 2: Top Obstacles as Perceived by Firms According to the 2014 Enterprise Survey

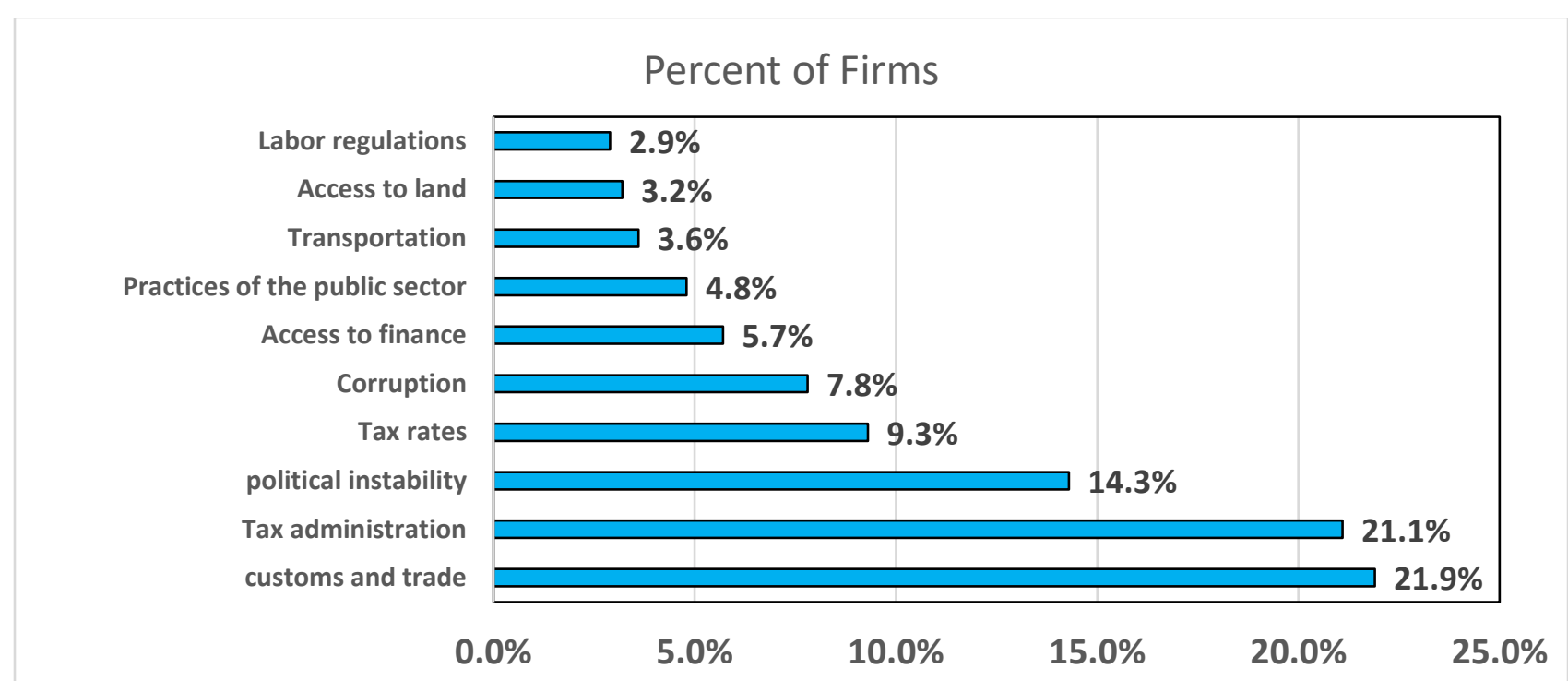

Source: World Bank (2014) Enterprise Survey.

The large presence of state-owned enterprises crowds out private sector investment. The broad range of activities in which the government participates as a direct or indirect owner of enterprises distorts competition in those markets, as the presence of state-owned enterprises provides a strong disincentive for private entry. In August 2018, it has been estimated that 431 government and 603 parastatal companies, out of the total 53,373 companies, have been registered under the company law throughout the country (Hassan 2019). However, it is not the number of companies but the size of this hidden economy that matters. Despite a government announcement in 2011, few state-owned enterprises or corporations have been divested/privatized. 


\section{Structural and Sector-Specific Constraints}

Several sectoral and structural constraints are directly affecting the MSME sector, including limited access to finance, inadequate infrastructure services (for example, electricity, storage, markets, and transport) and poorly trained work force, poor access to information and communication technology (ICT), and lack of technical support for small and micro enterprises (for example, incubation, capacity building, and incentive support).

A major constraint is financing, especially for MSMEs. The CBoS indicated, in its policy for 2018, that no less than 15 percent of the commercial banks' lending portfolio should be directed toward microfinance. A major constraint faced by small and micro enterprise clients in obtaining credit relates to 'transaction costs' since small enterprise loans are relatively small, while the cost of administering any credit is the same and does not vary with the loan size. This is complicated by the absence of efforts to adapt commercial banks to small and micro enterprise clients such as the provision of administrative capacity to handle small credit. Commercial banks have encountered many problems, and microfinance has not exceeded 6 percent of the banks' portfolios. The most recent Enterprise Survey (2014) indicates that only 4.6 percent of enterprises had access to a loan or line of credit from a bank, compared to an average of 22 percent for Sub-Saharan Africa. According to Findex (2014), only 15 percent of adults (age 15+ years) had a bank account, 8 percent saved in a formal financial institution, and 4 percent borrowed money from a formal financial institution. These percentages are below Sub-Saharan African averages. The situation is complicated further by weak credit insurance or guarantee schemes.

Sudan's lacks a modern credit reporting system and electronic collateral registry for movable assets, negatively affecting the willingness of lenders to extend credit to private enterprises, particularly to MSMEs. The absence of private credit bureaus as well as credit policies and management and staff culture limit the willingness of lenders to extend credit, particularly to small and micro enterprise clients. The practice of lending money against collateral is mostly limited to immovable property.

Little use of technology and untrained labor are major problems as weak technology and ICT hinder more efficient and productive business operations. In addition, untrained workforce due to weak technical education and vocational training institutions also inhibits development of efficient enterprise sector. The Government does not prioritize public expenditure for technical and vocational education and training. While secondary education grew by an increase in enrolments in the academic track over the last decade, enrolments in the much smaller technical track contracted (World Bank 2016, 48).

Given these constraints, the Sudanese Businessmen and Employers Federation proposed several policy reforms. The federation is the leading player of business institutions in Sudan and represents the vast majority of the private sector. The federation proposes policy reforms including macroeconomic stabilization measures and institutional reforms to improve the regulatory environment, the competitive environment for the private sector by reforming taxes and liquidating government companies, and ease of doing business. ${ }^{3}$

\footnotetext{
${ }^{3}$ The Sudanese Businessmen and Employers Federation: Policy Proposals in Support of the Private Sector on reforms needed in the 2018 budget.
} 


\section{MAIN FINDINGS OF THE SURVEY}

\section{Sudanese Enterprises Landscape}

Over 70 percent of the surveyed enterprises are micro, employing less than five workers, while the sector breakdown shows the dominance of retail and other services. Of the 489 surveyed enterprises using the World Bank Enterprise Survey Methodology, 353 are micro (employing less than 5 employees), 101 are small (5-19 employees), 23 are medium (20-99 employees), and the remaining 10 enterprises are large $\left(100+\right.$ employees). ${ }^{4}$ As noted earlier, Sudan has not yet developed a unified MSMEs definition. On the sector breakdown, the majority of the enterprises are retail and other services (Figure 3 ).

\section{Figure 3: Enterprise Size and Sector}

(a) Size

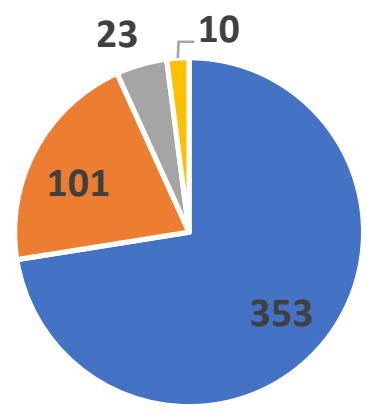
- Micro (0-4)
- Small (5-19)
Medium (20-99)
Large $(100+)$

Source: Sudan High Frequency Survey on COVID-19 (2020).

(b) Sector

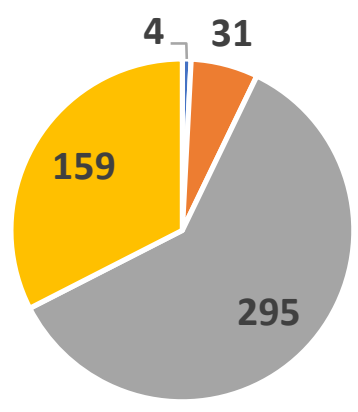

$$
\text { - Agriculture } \square \text { Manufacturing } \quad \text { Retail } \square \text { Other services }
$$

Source: Sudan High Frequency Survey on COVID-19 (2020).

\footnotetext{
4 The African Development Bank (AfDB) has developed a different definition of MSMEs where micro refers to 1-9 employees, small refers to 10-50 employees, medium refers to 50-250 employees, and large refers to more than 250 employees. However, AfDB's definition was applied to 45 Sub-Saharan African countries, excluding Sudan.
} 


\section{Impact on Operations Status}

Of the surveyed enterprises, 29 percent had to close during the partial lockdown, where 8 percent of surveyed enterprises permanently closed, and 21 percent temporarily closed (Figure 4). For permanently closed enterprises, 90 percent of them are expected to resume operation. However, time to resume operation varies from less than 2 weeks ( 27 percent), between 2 and 4 weeks ( 1 percent), between 1 and 2 months ( 13 percent), between 2 and 6 months ( 17 percent), and more than 6 months ( 28 percent) while some do not know when their businesses will resume operation (14 percent).

Figure 4: Disruptions to the Operation of the Enterprises (percentage)

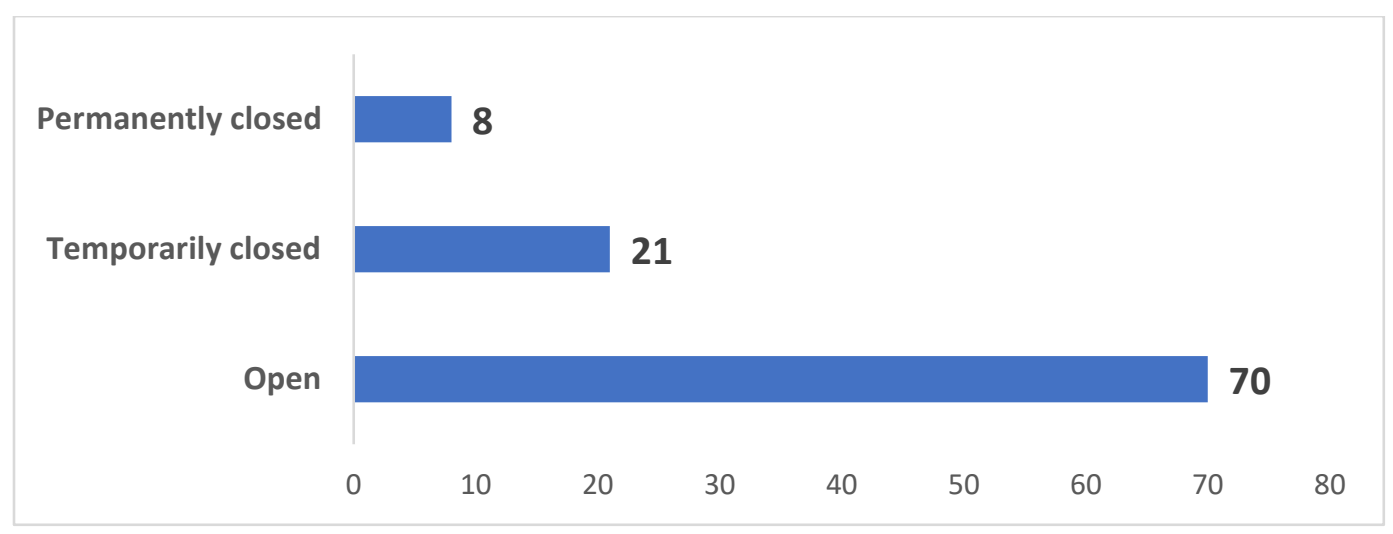

Source: Sudan High Frequency Survey on COVID-19 (2020).

On enterprise closing, small enterprises (5-19 employees) were the most affected by the partial lockdown where half (45 percent) had to close..$^{5}$ In contrast, around one-third of medium (20-99 employees) and large (100 and more employees) enterprises closed (Figure 5). While all enterprises were affected by the COVID-19 lockdown, those with smaller operating margins were the most affected.

\section{Figure 5: Disruptions to the Operations by Enterprise Size}

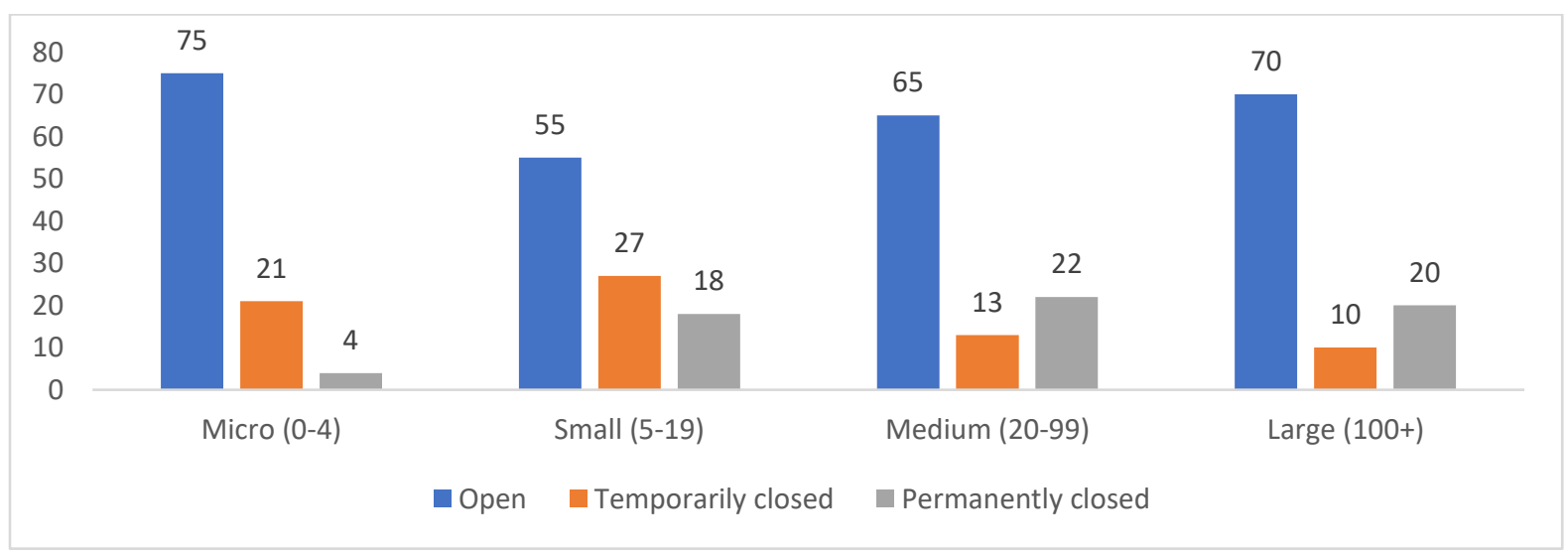

Source: Sudan High Frequency Survey on COVID-19 (2020).

\footnotetext{
${ }^{5} \mathrm{~A}$ further disaggregation of the micro enterprises by splitting own-account enterprises (those with only the business owner
} employed) indicates the small percentage of own -account enterprises that may not add much value to the analysis. 
The sectors with the highest level of closures during the lockdown were manufacturing and other services (about 50 percent), as shown in Figure $6 .^{6}$

Figure 6: Disruptions to the Operations by Sector

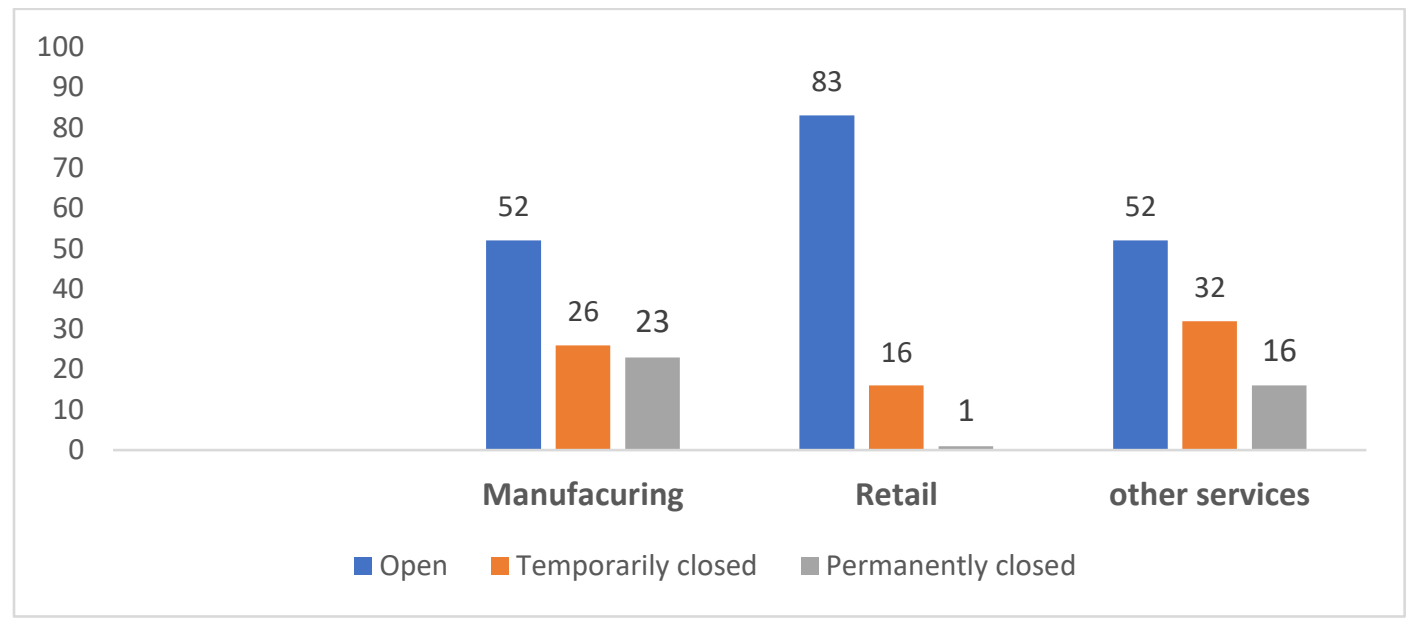

Source: Sudan High Frequency Survey on COVID-19 (2020).

\section{Impact on Sales and Employment}

Of the enterprises that are open, 81 percent reported that sales in August 2020 decreased compared to the same month in 2019 (Figure 7). The average decrease in sales is 54 percent. This corresponds to an estimated SDG 149,985. The average decrease in sales varies across sectors, that is, enterprises in manufacturing reported 83 percent reduction in sales, retail reported 68 percent reduction and other services reported 81 percent reduction. In terms of enterprise size, micro, small, and large enterprises reported more than 80 percent reduction in sales on average.

Figure 7: Change in Sales Relative to Same Period of 2019

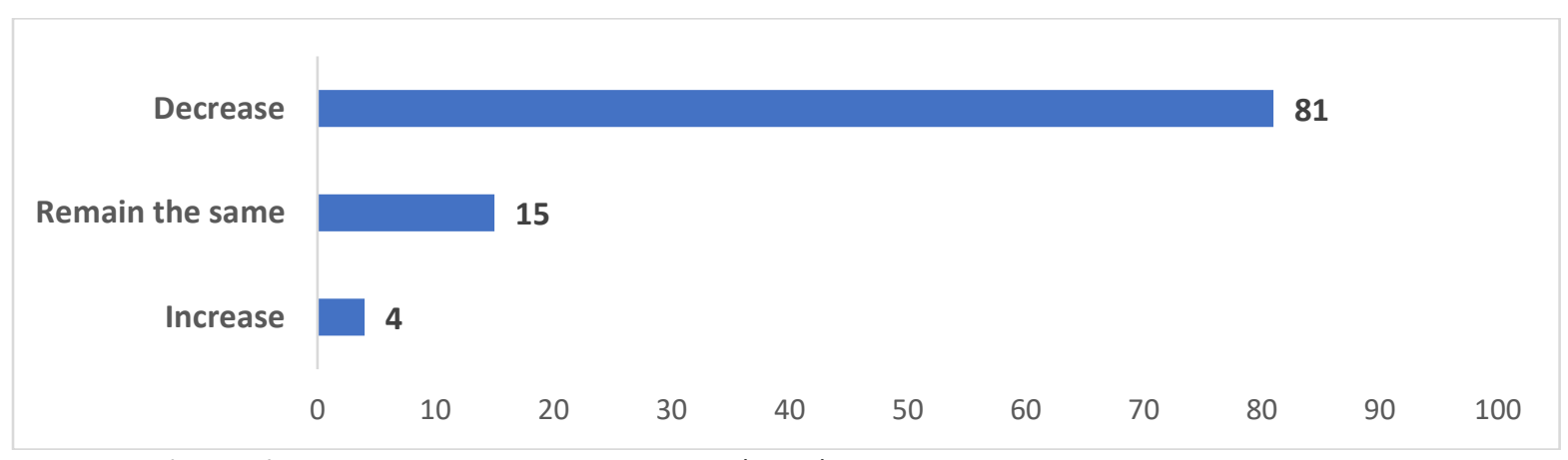

Source: Sudan High Frequency Survey on COVID-19 (2020).

The COVID-19 shocks forced enterprises to reduce costs by reducing staff hours (5 percent), cutting wages (7 percent), and in some cases laying off workers (8 percent), as shown in Figure 8. About 7 percent of the

\footnotetext{
${ }^{6}$ It should be noted that the number of agriculture enterprises surveyed is small (4 enterprises) as Khartoum is not an agricultural state, and hence, agricultural enterprises level of closure should be interpreted with caution due to a limited number of respondents and a limited geographic coverage focusing on Khartoum State.
} 
enterprises reported that they reduced wages for an average of 6 percent of their workforce (a total of 218 workers) while 8 percent of the enterprises indicated that they have laid off workers, corresponding to 5 percent of the workforce (a total of 131 workers).

Figure 8: Adjustments to Employment

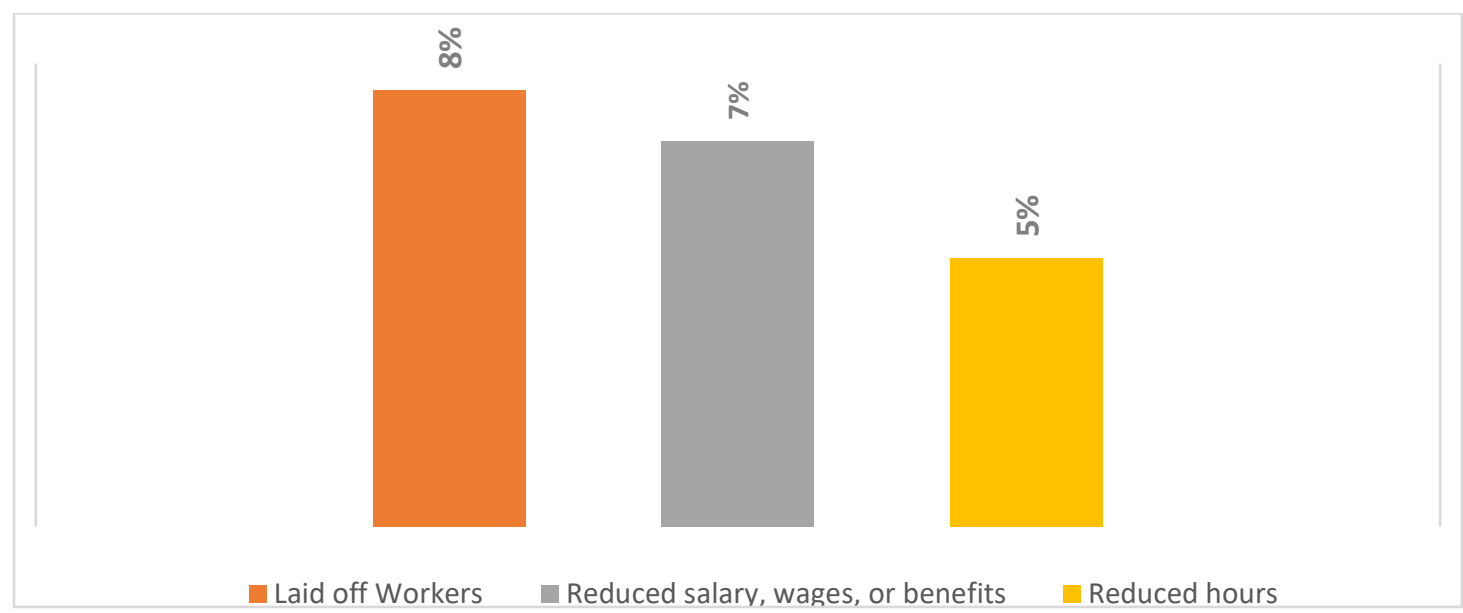

Source: Sudan High Frequency Survey on COVID-19 (2020).

\section{Channels Affecting Operations}

Nearly all enterprises (97 percent) indicated a decrease in hours worked, 87 percent witnessed a decrease in demand, 72 percent faced difficulties in finding input, and nearly 50 percent reported cash flow problems and decreased access to finance (Figure 9). These shocks are generally classified as demand shock (that is, decrease in demand) and production shock (that is, decrease in hours worked, cash flow, and availability of finance and inputs).

\section{Figure 9: Share of Enterprises Affected by Shocks}

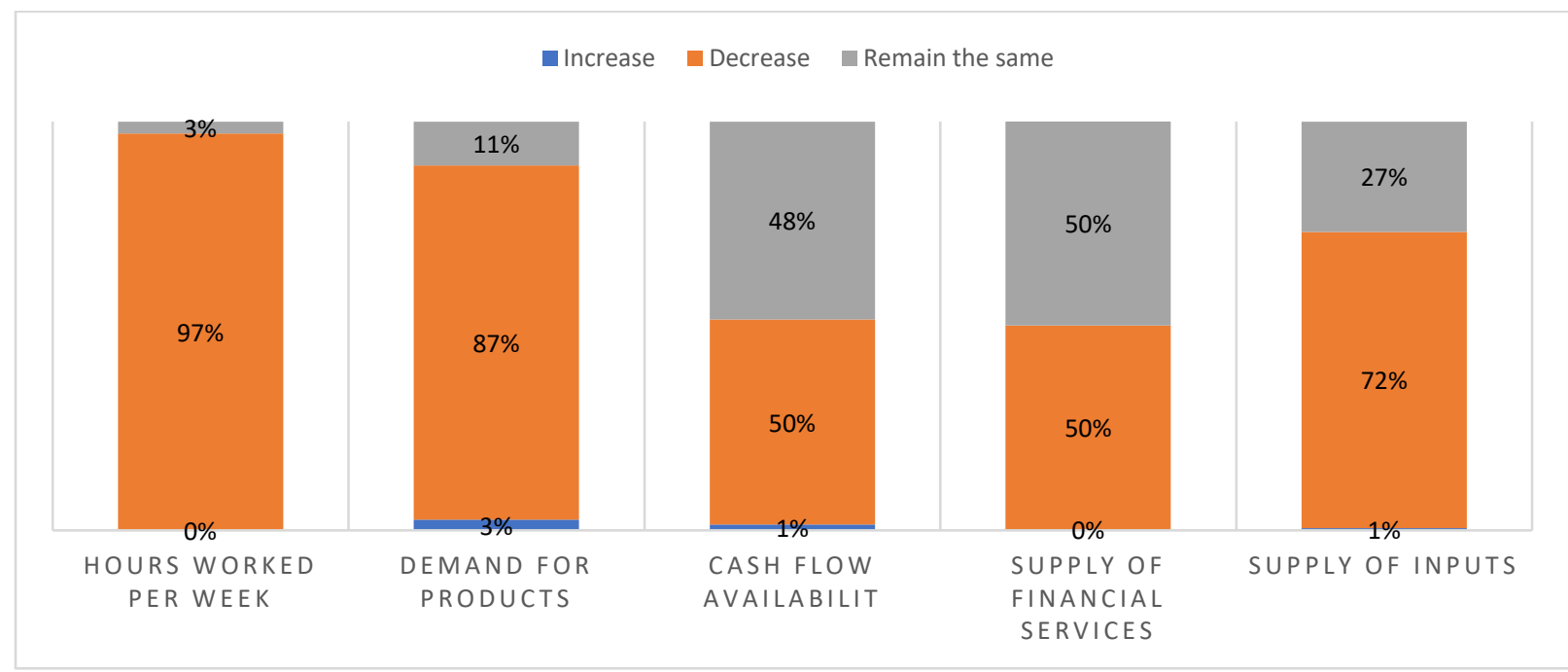

Source: Sudan High Frequency Survey on COVID-19 (2020). 
Significant differences exist in the share of enterprises affected by both demand and production shocks (that is, decrease in hours worked, cash flow, and availability of finance and inputs) by size and sector (Figure 10 and Figure 11, respectively). Medium enterprises (with a share of 93 percent) were the most affected, followed by the small and micro enterprises (with a share of 86 percent). Large enterprises (with a share of 70 percent) are more resilient to shocks than others. In terms of sector breakdown, the other sector (transport, storage, utilities) is the most affected (Figure 11).

Figure 10: Share of Enterprises Affected by Shocks by Size

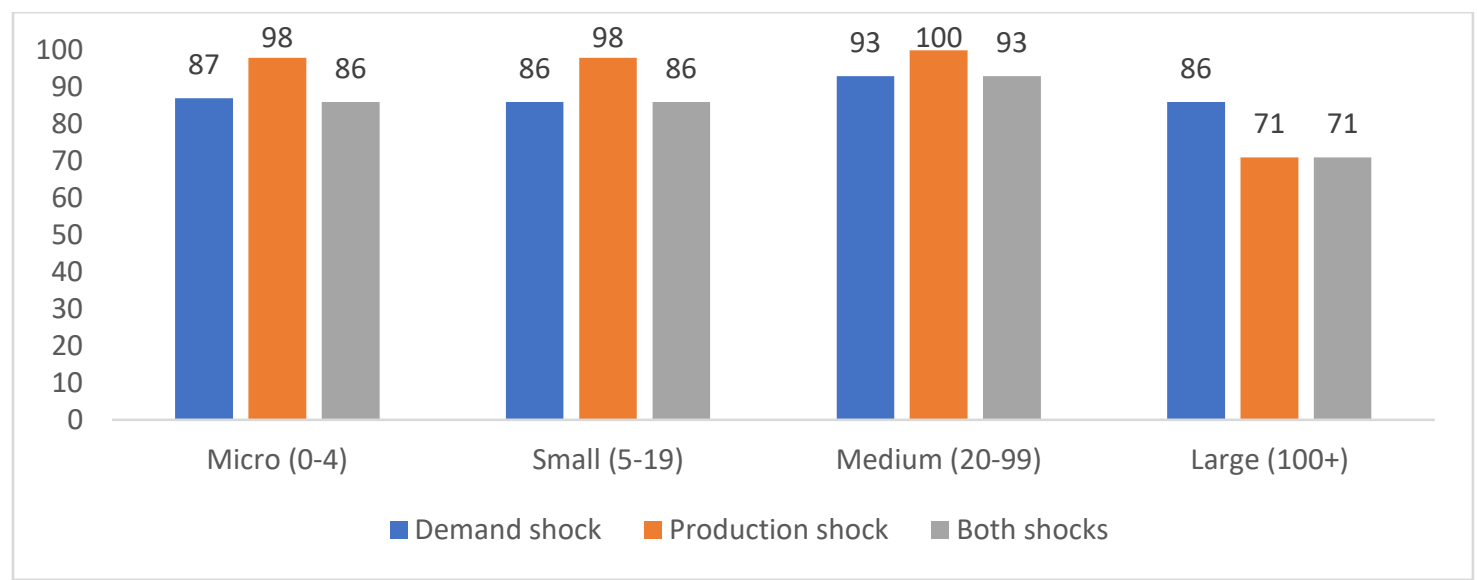

Source: Sudan High Frequency Survey on COVID-19 (2020).

Figure 11: Share of Enterprises Affected by Shocks by Sector

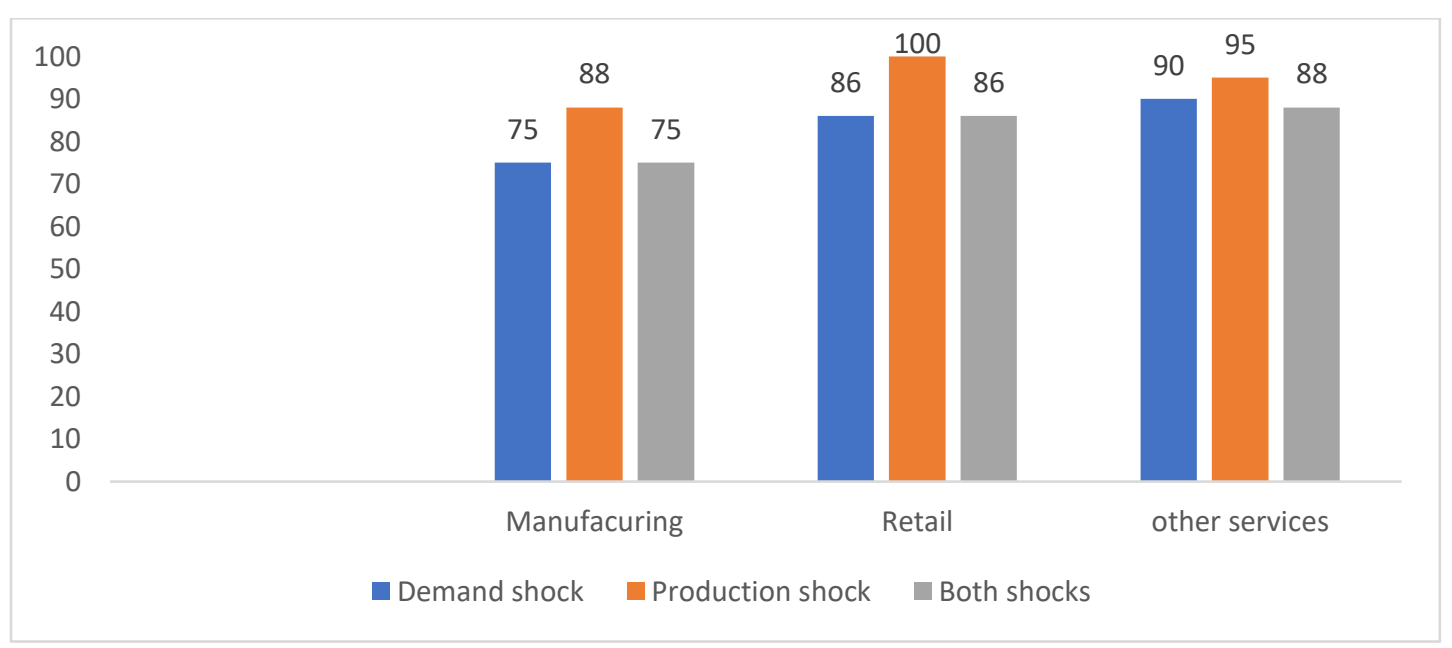

Note: Shocks are grouped into demand (decrease in demand) and production shocks (decrease in availability of inputs and reduction in hours of operation.

Source: Sudan High Frequency Survey on COVID-19 (2020).

\section{Adjustment Mechanism/Digital Solutions}

To adjust to the COVID-19 measures, about 11 percent of the enterprises started or increased their use of internet, online social media, specialized apps, or digital platforms to do business. However, the share 
of enterprises that started or increased their use of the internet varies substantially. Large enterprises' use of internet far exceeds other categories (Figure 12).

\section{Figure 12: Share of Enterprises Using Digital Solutions}

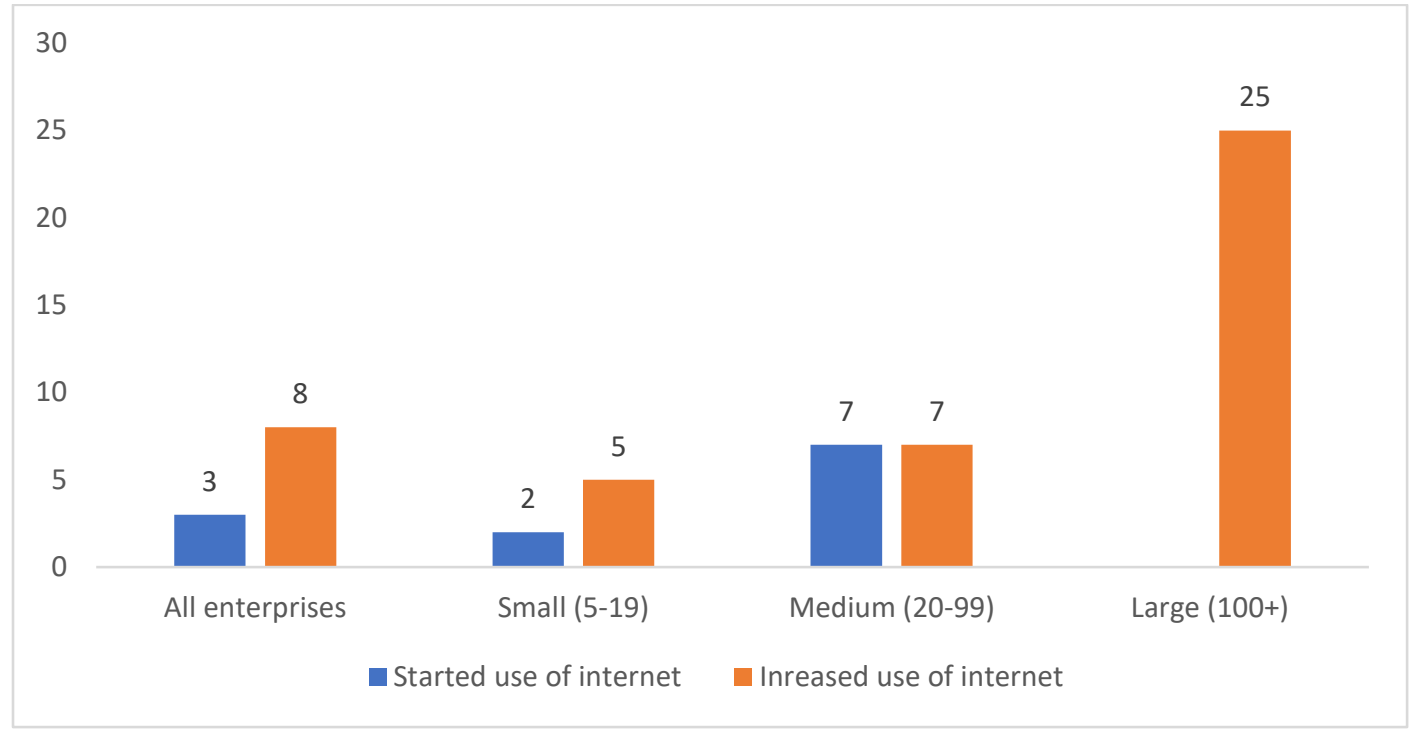

Source: Sudan High Frequency Survey on COVID-19 (2020).

\section{Enterprise Perceptions and Government Policies}

As noted earlier, the Government prepared the Multi-hazard Emergency Health Preparedness Plan, and the financing needs to cope with COVID-19-related health care are estimated at US\$230 million. Although the federal budget for 2020 includes a major emergency allocation of resources for COVID-19-related expenditures, the plan remains underfunded and the needs are imminent especially with the expected second wave and the recent deadly flooding in the country. The World Bank approved a grant of US\$21.99 million to help Sudan mitigate the effects of the COVID-19 pandemic. $^{7}$

However, the COVID-19 pandemic, while a public health emergency, has turned into a global economic crisis. COVID-19-related restrictions on economic activities and populations movements are exacerbating Sudan's long-standing macroeconomic crisis. This is resulting in significant decreases in income-earning opportunities and employment, alongside continued reductions in the value of the Sudanese pound and high prices for fuel and food. Staple food prices, including sorghum, millet, and wheat, have increased by 20-50 percent over the past July and August months and remain several times higher than the recent fiveyear average. These high prices, in combination with significant reductions in labor income, are likely to continue driving well above available resources to meet household and enterprise needs. While the government has provided a family support program (cash transfers) to poor households during the pandemic, enterprises are not included. ${ }^{8}$ In fact, enterprises have not received any monetary transfers or tax exemptions. In contrast, governments around the world pumped trillions of dollars into their countries

\footnotetext{
7 Of the total amount provided, US\$6.5 million is provided by the Health Emergency Preparedness and Response Trust Fund (HEPRTF) and U\$15.49 million is provided by the Sudan Transition and Recovery Support Trust Fund (STARS) (World Bank 2020b). 8 The World Bank and key partners are supporting the Sudan Family Support Program that provides cash transfers to poor Sudanese households.
} 
to save nations from collapsing. Moreover, the government has increased public sector wages in June 2020, while the private sector has experienced difficulties meeting staff wages.

The Government has implemented a limited number of policies to support the enterprise sector. The enterprise sector has been operating in a restrictive policy environment. Prior to COVID-19 pandemic, the Central Bank of Sudan directed commercial banks to allocate 15 percent of their portfolio to microfinance. Although this microfinance policy was adopted in 2018, the actual amount allocated to microfinance is about 6 percent. More importantly, SMEs are not targeted by the initiative. The CBoS has asked commercial banks to provide some concessions to enterprises in terms of loan payment deferral following the pandemic. However, these measures have not been effectively communicated to the enterprise sector.

Strengthening the institutional framework to support enterprise private sector development will be key to streamlining and accelerating the reform process. The GoS created the Investment and Private Sector Development Authority (IPSDA) in December 2019 as a one-stop-government institution to cater for the private sector, its needs and challenges. IPSDA has already embarked on its reform agenda, including drafting of a new Investment Law and Public- Private partnership Law. This is a first step towards leading a sector focused policy, regulatory reforms and institutional coordination. Previously, IPSDA's role was distributed among multiple agencies including the Ministries of Industry, Ministry of Investment and Trade, and Ministry of Social Development and Labor. The dedicated Authority will house specialized units, focused on Investment Climate, Public-Private Partnerships, the Micro, Small and Medium Enterprise and Entrepreneurship Development, and Free Economic Zones. The Authority will lead the national private sector development agenda, investment vision and policy framework to achieve key state level development and investment targets. Public-private dialogue (PPD) forum will be deployed to ensure full stakeholder alignment and coordination. The Government has set a target to enhance its Doing Business Index ranking by 20 points in the coming 4 years from its current rank of 171 . The streamlining of the investment climate agenda under IPSDA will help coordinate and monitor reforms in the arears of business registration, dealing with licenses and permits, registering property and others. Attention should be paid on the implementation of the vision for the IPSDA to strengthen the institutional framework to support the private sector in Sudan, following the change in management as the new director has not yet been appointed.

Enterprises faced significant financial problems during the COVID-19 outbreak. Financial problems are perceived by enterprises as top obstacles according to the Sudan High Frequency Survey on COVID-19 (2020). These financial problems include meeting staff wages and social security charges, paying rent, repaying loans, and paying invoices (Figure 13). 
Figure 13: Most Significant Financial Problems for the Enterprise during COVID-19 Outbreak

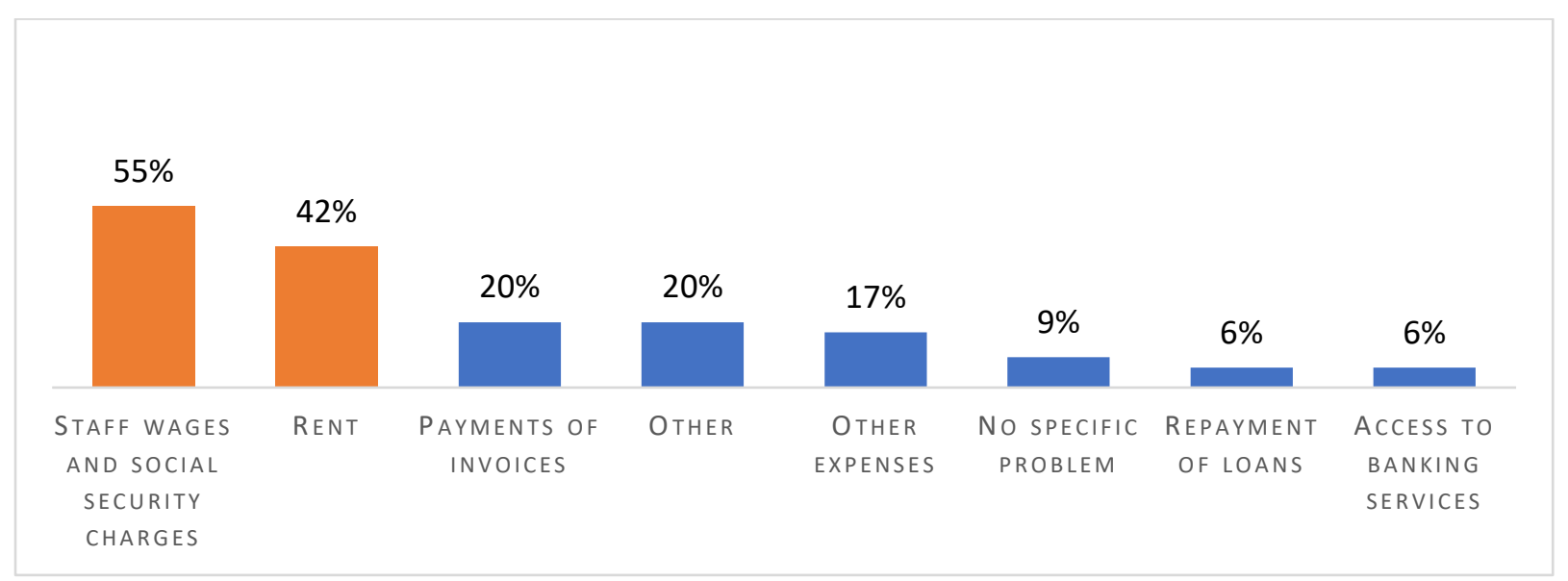

Source: Sudan High Frequency Survey on COVID-19 (2020).

Surveyed enterprises report that measures improving liquidity (cash transfers, fiscal exemptions or reductions, tax deferral, access to new credit, and deferral of rent payment) are the top five most desired policies to support enterprises during the pandemic (Figure 14).

Figure 14: Self-Reported Most Needed Public Policies to Support Enterprises during the Pandemic

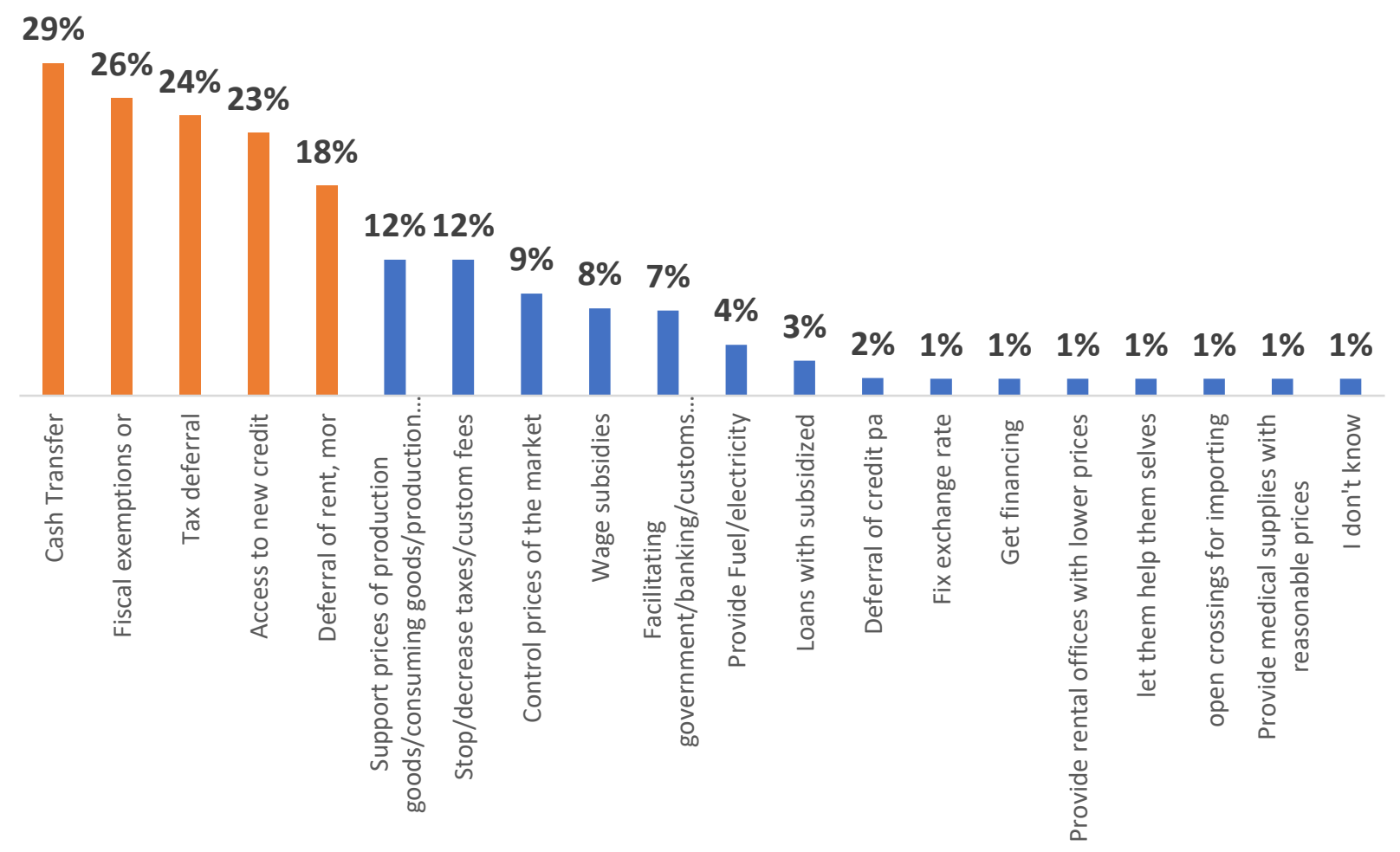

Source: Sudan High Frequency Survey on COVID-19 (2020). 
None of the surveyed enterprises received public support and 62 percent of them indicated that they were not aware of support programs (Figure 15). These findings do not differ among enterprises (Figure 16). Careful consideration needs to be given to increased awareness and clarity on the guidelines and requirements of public support programs.

Figure 15: Reasons Why Enterprises Have Not Received Public Support

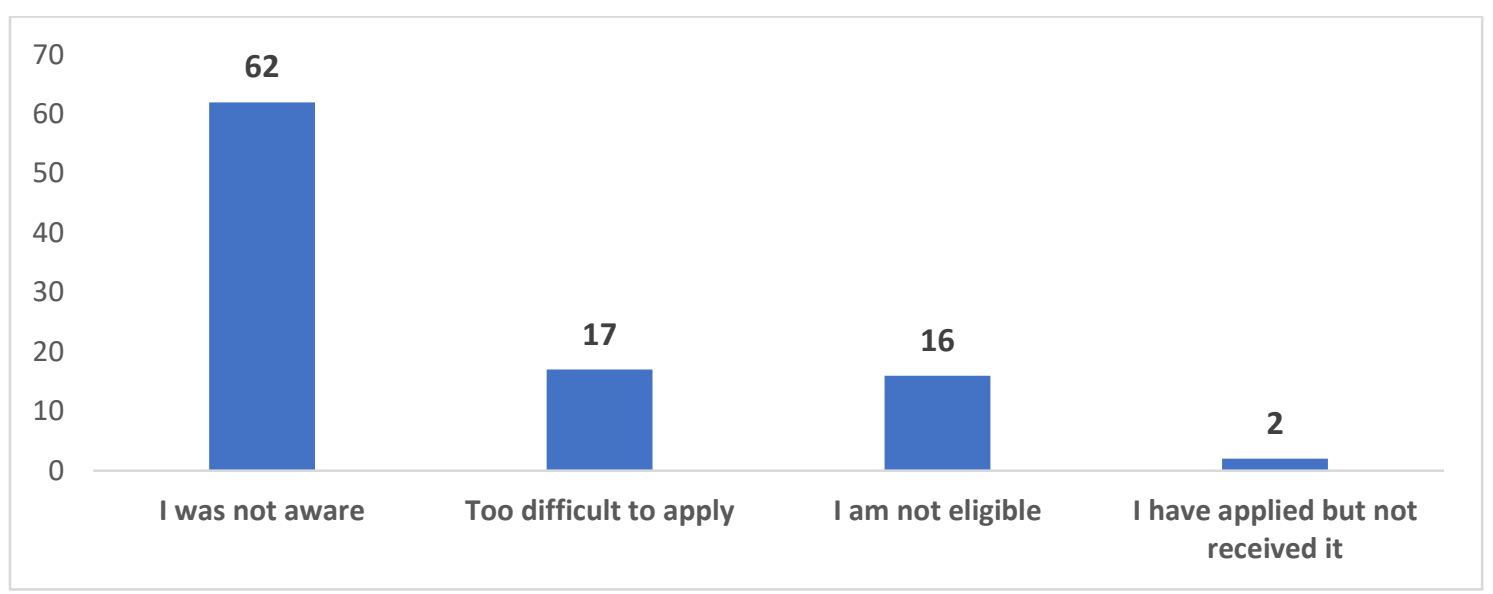

Source: Sudan High Frequency Survey on COVID-19 (2020).

Figure 16: Reasons Why Enterprises Have Not Received Public Support, by Size

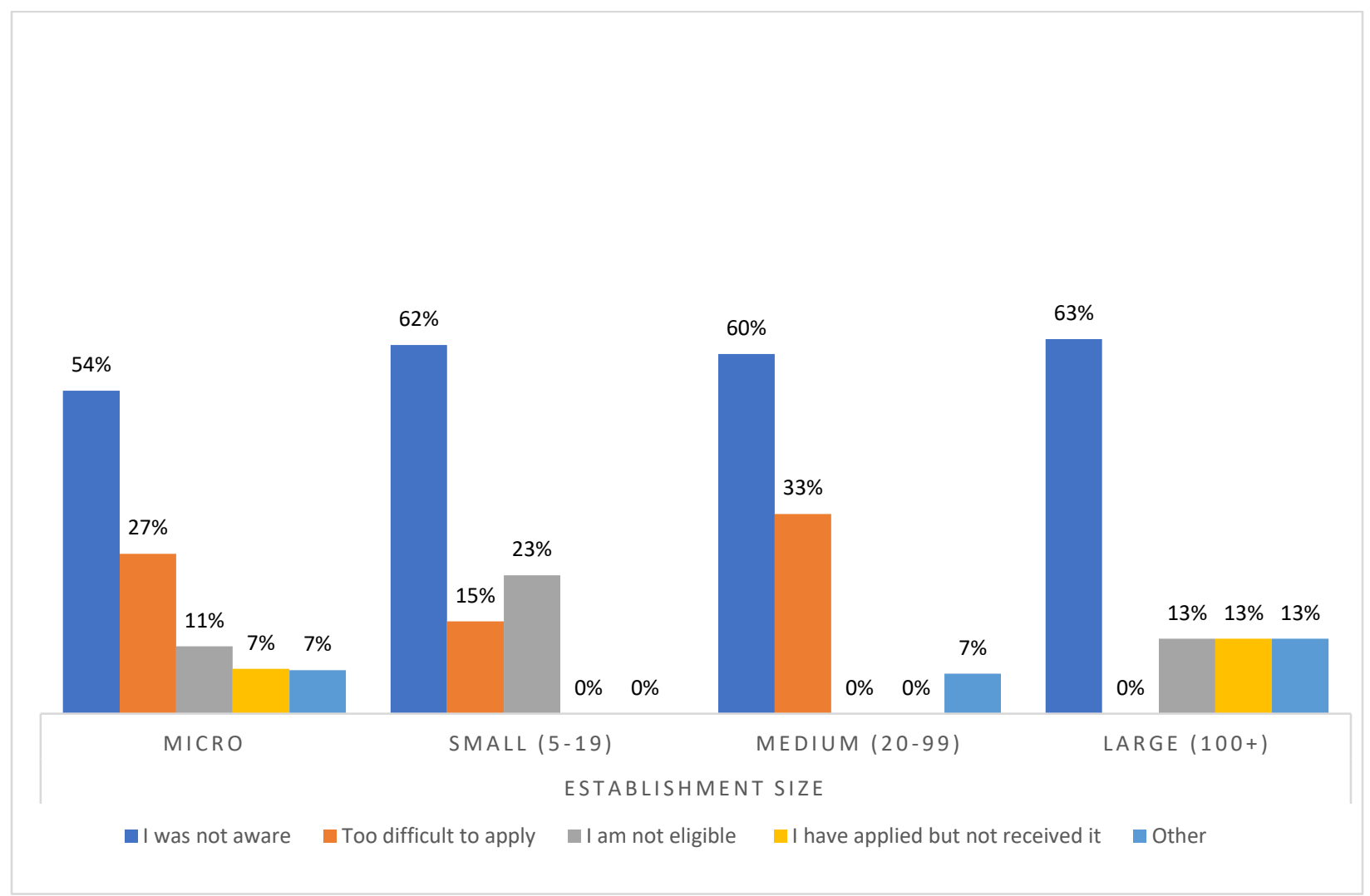

Source: Sudan High Frequency Survey on COVID-19 (2020). 


\section{Limitations of the analysis}

The findings presented above are based on a short survey administered by telephone to assess the effects of the COVID-19 pandemic and the data did not include women-owned and informal enterprises. The data coverage did not include informal enterprises that may be exposed to disruptions due to lack of assets and limited access to services and formal financial sources. Furthermore, they are non-tax paying enterprises with no access to public services and training activities, limiting their chances to benefit from market linkages, formal contracts or investments. These indicators need to be explored. An illustration of female participation in management and enterprise ownership is missing though a recent study by the IMF shows that Arab countries, including Sudan, have one of the lowest shares of women-owned SMEs at 14 percent, compared to the world average of 34 percent (IMF 2019). The analysis of women-owned enterprises can help assess whether gender can be a determinant of the effect of regulations on the enterprise and the level of exposure of the enterprise to shocks, such as supply of inputs, access to cashflow, finance, and technology.

\section{SUMMARY AND POTENTIAL POLICY RESPONSES}

Utilizing data from the Sudan High Frequency Survey on COVID-19, this report analyzes the impact of the pandemic on Sudanese enterprises through several channels. These include disruptions to operations and closings, impacts on sales and employment, demand and production shocks affecting businesses, adjustment mechanisms, enterprise perceptions, and government policies. The key findings are that the COVID-19 pandemic has-through the abovementioned channels-badly hurt enterprises of all kinds, particularly those with smaller operating margins, such as MSMEs. Business and liquidity have dried up. Jobs have been lost, and entrepreneurs have drastically curtailed if not closed their businesses.

Assessing the impact of the COVID-19 pandemic on Sudanese enterprises is not an easy task as a confluence of other factors may be affecting enterprises at the same time. That is, in addition to the COVID-19 impact, major factors are affecting the performance levels of business enterprises. These factors include political instability, macroeconomic uncertainty, particularly inflation and exchange rate volatility (adversely affecting enterprises' ability to predict their business future), a weak financial system (liquidity constraints and inability to borrow to cover operations cost including wages, rent, and bills), a disadvantageous business environment climate (onerous customs and taxes procedures), and poor infrastructure (electricity, internet, and broadband).

\section{Potential Policy Responses}

Mitigating the COVID-19 impacts and addressing several constraints affecting the performance of the enterprise sector require a holistic policy approach: (a) accessing liquidity and finance schemes, (b) enhancing governance and an enabling business regulatory framework, and (c) leveraging technological progress to 
upgrade infrastructure. The approach encompasses short- and medium to longer-term policy response as detailed below.

Immediate COVID-19 response interventions include designing enterprise support schemes and facilitating access to finance:

- $\quad$ Providing incentive support that improves enterprise liquidity such as cash transfers and deferral of payments to ensure that businesses are returned to their state before the pandemic. Enterprises report that measures improving liquidity are the most desired policies, and these policy responses are expected to help enterprises sustain their activities and minimize layoffs.

- Boosting financial access by improving the availability of adequate funding adapted to enterprise needs. Suggested policy measures include strengthening the financial system, developing a modern credit reporting system and electronic collateral registry for movable assets, and adapting commercial banks to small and micro enterprise clients These measures would enable lenders to extend credit to private enterprises, particularly to MSMEs.

Medium to longer-term interventions focus on strengthening the business climate:

- $\quad$ Enhancing the governance system of enterprises. Sudan still does not have a law to support small and micro enterprises nor a specialized national entity dealing with their specific needs and challenges. The overlap of the roles and responsibilities of the institutions responsible for MSMEs and weak coordination among them limits their capacity to set policies, strategies, and plans for their development. The recent establishment of the Investment and Private Sector Development Authority is a first step towards leading a sector focused policy, regulatory reforms and institutional coordination. Strengthening the capacity of the Authority will be key to streamlining and accelerating the reform process.

- $\quad$ Addressing enterprise data gaps. An effective data collection framework should be developed that includes demographic data on MSMEs by number of employees, turnover, and asset size, to standardize the definition of MSMEs. In addition, supply-side data should be collected by the central bank/banking supervisors and other financial supervisors and enterprise surveys to identify and quantify underserved MSMEs segments. Computerized business registries would further facilitate the data gathering process and would serve as an important first step for enterprises joining the formal sector. Annual business and financial reports can provide important measures over time on the size and trends of the MSME sector.

- Leveraging technological progress to ensure access to reliable key infrastructure, such as internet and broadband, would enhance enterprise capabilities to cope with the COVID-19 pandemic and other shocks. Sudanese enterprises' use of internet to do business is one of the lowest in the world. Pursuing policies that facilitate the adoption of digital solutions helps enterprises expand access to new markets and inputs and in turn could help sustain or increase their production level. 


\section{REFERENCES}

Dabalen, A., A. Etang, J. Hoogeveen, E. Mushi, Y. Schipper, and J. von Engelhardt. 2016. Mobile Phone Panel Surveys in Developing Countries: A Practical Guide for Microdata Collection. World Bank Publications.

Hassan, Fareed. 2019. Supporting Job creation and Economic Growth in Africa: Jobs and Growth Compact for Sudan. Technical Assistance to the EU Delegation for Cooperation in Sudan. Khartoum, Sudan.

IFC (International Finance Corporation). 2010. Scaling-up SME Access to Financial Services in the Developing World. IFC, Washington, DC: World Bank Group.

IFC. 2017. Overcoming Constraints to SME Development in MENA Countries and Enhancing Access to Finance. IFC, Washington, DC: World Bank Group.

IMF. 2019. Enhancing the Role of SMEs in the Arab World: Some Key Considerations. Washington, DC: IMF.

Leo, B., R. Morello, J. Mellon, T. Peixoto, and S. T. Davenport. 2015. “Do Mobile Phone Surveys Work in Poor Countries?" Center for Global Development Working Paper 398.

World Bank. 2014. Enterprise Surveys: Sudan. Washington, DC: World Bank Group.

World Bank. 2016. The Sudan Interim Poverty Reduction Strategy Paper Status Report. Washington, DC: World Bank Group.

World Bank. 2019. Enabling the Business of Agriculture. Washington, DC: World Bank Group.

World Bank. 2020a. How COVID-19 Is Affecting Firms in Ghana. Washington, DC: World Bank Group.

World Bank. 2020b. Country Engagement Note for the Republic of Sudan (FY21-FY22). Washington, DC: World Bank Group. 